\title{
Conflicts of Vowel Governed Constraints in Arabic Derivation
}

\author{
Fareed Hameed Al-Hindawi, Dhaifullah Zamil Al-Jashamy ${ }^{*}$ \\ Department of English, College of Education, Islamic University, Najaf, Iraq \\ Email address: \\ fareedhameed3@Gmail.com(F. H. Al-Hindawi),dhaifullah.z1989@Gmail.com (D. Z. Al-Jashamy) \\ ${ }^{*}$ Corresponding author
}

\section{To cite this article:}

Fareed Hameed Al-Hindawi, Dhaifullah Zamil Al-Jashamy. Conflicts of Vowel Governed Constraints in Arabic Derivation. Arabic Language, Literature \& Culture. Vol. 6, No. 2, 2021, pp. 37-42. doi: 10.11648/j.allc.20210602.12

Received: February 20, 2020; Accepted: March 1, 2020; Published: May 14, 2021

\begin{abstract}
The paradigm of constraints that is proposed by optimality theory as a substitute to the rules paradigm has influenced all the fields of linguistics. Different phonological phenomena in different many languages have been investigated in terms of optimality theory. The phonological structures of Arabic suffer from some changes like deletion, substitution and other processes that underlie the systematic derivation (Al-ishtiqaaq) of vowels. In terms of Optimality Theory, this paper investigates two issues: First, the conflicted faithfulness and markedness constraints that govern vowels through derivation, and second, how these constraints are ranked. Finding out such constraints can provide the storage of the universal constraints by new ones and discovering how Arabic ranks these universal constraints. The current study adopted the mechanism that is proposed by the optimality theory. At the same time, the paper suggested some constraints that has been tested and formulated according to the theory in question. The ranking of these constraints also have been investigated. The study led to demonstrating the existence of the suggested constraints that work during derivation. It also represented how these constraints are ranked. Some of the discovered constraints are already found in the universal storage of constraints and others are peculiar to Arabic. It is found that the SAK constraint (the absence of the Arabic short vowels) plays a fundamental role in vowels derivation.
\end{abstract}

Keywords: Arabic Derivation, Optimality Theory, Vowel, Constraints, Ranking, Deletion, Substitution

\section{Introduction}

Optimality theory (OT) has inspired linguists from different areas or fields of linguistics. Sounds system of many languages, like Spanish [1], [2], have been investigated by using this paradigm, OT. Many Arabic phonological phenomena have not received studies within the OT framework, therefore, the current study is oriented to bridge part of the gap. One of the prominent aspects of Arabic is its great capacity to produce new words by derivation or what is known in Arabic as Al-ishtiqaaq. It is the process of deriving a group of related words, sometimes ten or more, with similar meaning from a single root. English words can be formed by adding, for example, an affix (possible) to the root (impossible). Unlike English, Arabic words are not formed by adding affixes. Instead, derivation is achieved by making changes in the 'templates' of words: various combination of consonants and vowels. One of the common phenomenon that combines derivation is the changes that happen to vowels like deletion and substitution. This paper is based on two central research questions: what is the system that governs derivation regarding vowels? And how does this system work? Besides, the current work adopts the Optimality Theory (OT) as a phonological framework in its attempts to find answers to the research questions raised above. OT is one of the most revolutionary sophisticated phonological theories in the recent decades. It has led to a dramatic change in the way we look to language in general and phonology in particular. In terms of this theory, this paper aims to find out the constraints that govern vowels during derivation and how these constraints are ranked in order to select the optimal vowel forms. Finding out such constraints will provide the storage of the universal constraints with new ones and discovering how Arabic ranks these constraints. The paper consists of two sections: The first contains a brief account of OT. The second involves the 
proposed constraints that govern vowels during derivation, their analysis in five general cases and the general ranking of the constraints.

\section{OT as a Framework of Analysis}

One of the most important developments within the framework of generative grammar is Optimality Theory (OT) proposed by Prince and Smolensky [3]. This theory is highly applicable not only to phonology, but also to morphology, syntax, semantics, pragmatics, and language acquisition. Archangeli describes Optimality Theory (OT) as "THE Linguistic Theory of the 1990s," [4]. OT has led to the most important shift from Chomsky and Halle restrictedly ordered abstract rules to more free concrete constraints [5]. One of the motivations that paved the way to the appearance of OT is the phonological conspiracies phenomenon- several rules work to achieve the same representational goal, which cannot be explained by the classical rules [6]. OT views grammar as a "system of conflicting forces". These forces are represented or embodied by universal constraints. Constraints are in conflict in the sense that satisfying one constraint leads to violating another. No linguistic structure can pass the evaluator without violation of some constraints [7]. Through his discussion of the distinguishing feature of disjunctive, Baković demonstrated that OT, as a phonological paradigm, is more sophisticated than SPE in many areas [8]. OT has been employed to solve problems in programming language because of its flexibility in taking into account the context dependent changes of sounds [9].

OT skeleton consists of three main components which in turn consist of other sub-components. The phonological processes start from the lexicon of lexical representation which forms the input. The input will be sent to the second component, the Generator (GEN), which generates a number of candidates. These candidates will be sent to the third component, the Evaluator. The evaluator selects the optimal candidate to be the vocalized output (See Figure 1).

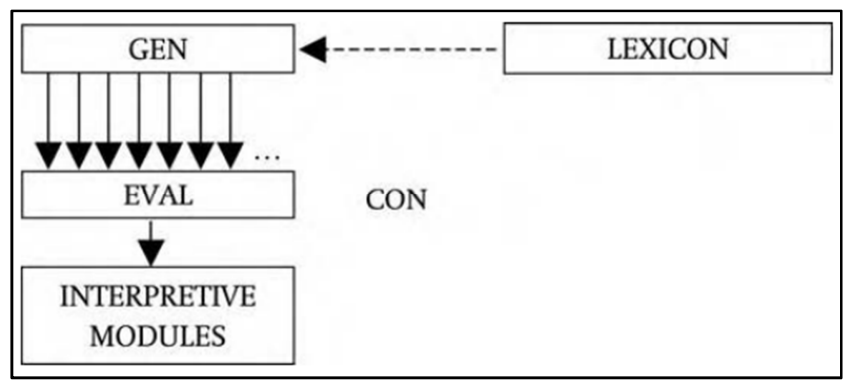

Figure 1. The Architecture of OT [10].

All the contrastive features of a language's morphemes (affixes, stems and roots) are found in the lexicon. These are semantic, syntactic, morphological and phonological features. The lexicon specifies the input with all these features in order to submit it to the generator. One of the main OT tenets in this context is that these specification operations are stated at the underling representation [7]. This tenet is based on the notion of Richness of the Base. According to this notion and given a suitable ranking of constraints will be explained in the next section. A speaker can produce any form of a stored group of related forms, there are all the possible forms of a word, not only one word. For instance, the surface form [ $\left.\mathrm{k}^{\mathrm{h}} æ \mathrm{t}\right]$, is selected among the other possible forms such as $/ \mathrm{k}^{\mathrm{h}}$ æt/, $/ \mathrm{kæt} /$ or $/ \mathrm{k}$ !æt/. Such a surface form is got as a result of putting constraints which advocate aspirated stops at the initial of word at a high position in the ranking [11].

The lexicon feeds the GEN by the input. The most prominent property of GEN is its universality. It is universal in the sense that the candidates or forms of a given input that the GEN emits are the same in all languages. The candidates are infinite and highly diverse. This feature is known as freedom of analysis. The universality of GEN forces it to generate a great number of various candidates that cover all the diverse languages. For instance, languages differ in syllabifying the consonant cluster as $b r$ (in Arabic jab.rI while in English alge.bra), therefore GEN will generate all the possible candidates including jab.rI and alge.bra. The constraints ranking of a specific language will determine which candidate must be selected [12]. Generating all the possible candidates of a given input excludes any need for rewrite rules to derive the output from the input. All these operations in the GEN are applied in parallel in one step [7]. GEN is described as input dependent. The released candidates keep some kind of determinate relationships or connections with some sort of the given input form. These relationships might be phonological, morphosyntactic, or syntactic "feature specification". By specific means, the candidates record the way they differ from the given input. The constraints, discussed in the next section, use this record to gauge whether a candidate is faithful to the input or not. Different implementations of this core idea have been imagined and investigated, as in Chomsky's trace theory [13], candidates differentiate derived features structurally. Every candidate retrieves some traces that reveal the way it has been produced [12].

Constraints are the landmark which distinguish OT as a constraints-based approach of phonology. Constraints are described by their two prominent features: universality and violability. Universality of constraints indicates that they are components of all natural grammars. However, this does not mean that a constraint will be active in the same degree in all languages. Unlike the inviolable rules, these universal constraints must be violable to account for the language specific issues. The various degrees of violability of a constraint in languages are based on language specific ranking. Violation is not motivated and it must be as minimal as possible. A candidate tends to violate low ranked constraints to avoid violation of the high ranked ones that may put it out of the competition [7]. The violability in question differs from parametrization. Parameters are either selected and completely active in one language or totally excluded: syllables of a language must take onsets or must not. Unlike parametrization, the violation provides a high 
degree of flexibility [12].

There are two types of constraints: faithfulness and markedness. Faithfulness constraints prevent the output to be different from the input. They are against deletion and shortening of vowels during mapping between the underlying /taxa:-k?a/ and surface [ta.xak?] [14]. McCarthy \& Prince posit three fundamental families of faithfulness constraints [15]:

(1) a. MAX prevents deletion.

b. DEP prevents epenthesis.

c. IDENT (F) prevents exchanging the value of feature $F$.

Markedness constraints, on the other hand, are blind to the input, they refer only to the output. Kager measures the output according to "structural well-formedness" [7]. These constraints prevent marked structures; (2) below shows some of these constraints that Prince and Smolensky propose [3].

(2) a. NUC: Syllables must have nuclei.

b. -CODA: Syllables must have no codas.

c. ONS: Syllables must have onsets.

d. HNUC: A nuclear segment must be more sonorous than another

e. *COMPLEX: A syllable must be V, CV or VC.

f. CodaCond: Coda consonants cannot have place features that are not shared by an onset consonant.

g. NonFinality: A word-final syllable (or foot) must not bear stress.

h. FtBin: A foot must be two syllables (or moras).

i. Pk-Prom: Light syllables must not be stressed.

j. WSP: Heavy syllables must be stressed.

The conflict between constraints leads to that, at least, some of them are violated by all linguistic structures. This does not mean that the output is ungrammatical since violability and restricted ranking are prominent properties of constraints. The optimal candidate or output can be defined or selected in these circumstances according to prioritization of constraints, as in Figure 2. OT suggests that some constraints have the priority above the others according to a specific language. If the constraint $\mathrm{A}$ has the priority above $\mathrm{B}, \mathrm{A}$ will be ranked above $\mathrm{B}$. They are written as $\mathrm{A}>>$.

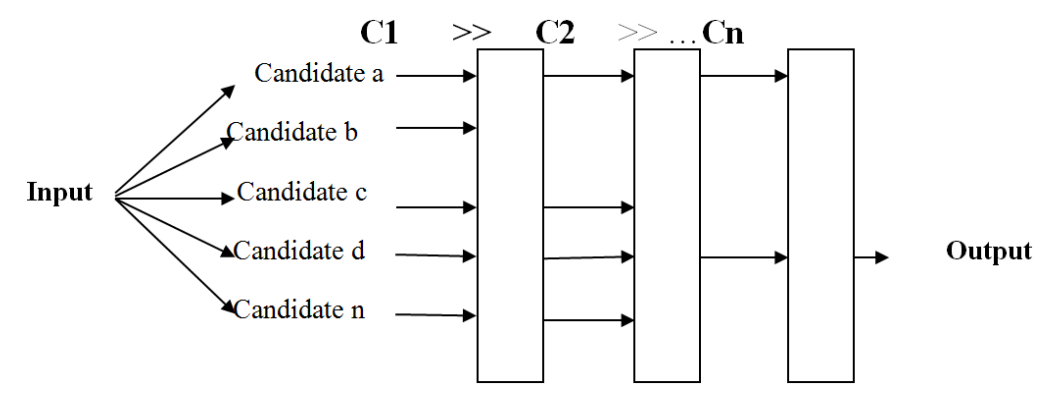

Figure 2. Mapping of input to output in OT grammar [7].

The analysis in OT is represented in a table. It shows the mapping from the underlying representation to the surface representation, the winner, as in Figure 3. The main concern for the current situation is how the table can be read. The first column contains the input and all the possible candidates. 'The pointing hand' marks the optimal candidate. Each of the rest columns is specified to a particular constraints, C1, C2, $\mathrm{C} 3$, etc.. The solid lines between the columns indicate that the constraints have different ranks, while the dotted ones refer to the same rank of the two constraints. The sign $(*)$ is used to mark violation of a constraint, and (!) marks the fatal violation. The shadowed blanks are not important in making the decision about the optimal choice [10].

\begin{tabular}{|c|c:c|c|c|}
\hline |input| & $\mathrm{C}_{1}$ & $\mathrm{C}_{2}$ & $\mathrm{C}_{3}$ & $\mathrm{C}_{4}$ \\
\hline $\mathrm{\sigma}$ (a) cand $_{1}$ & & & $\cdot$ & $\cdot$ \\
\hline (b) cand $_{2}$ & & & $\cdot$ & $\cdots !$ \\
\hline (c) cand $_{3}$ & & $* !$ & & $\cdot$ \\
\hline (d) cand $_{4}$ & $* !$ & & & \\
\hline
\end{tabular}

Figure 3. Sample of the Table [10].

\section{Arabic Vowels and the Suggested Constraints}

During derivation there are a number of constraints that are applied to vowels in different cases and positions. Vowels play a fundamental role in building syllables, since Arabic prohibits consonant cluster. Therefore Arabic draws heavily upon the markedness constraint *COMPLEX. Vowels are two main types: long vowels and short vowels. Long vowels are: $/ \overline{\mathbf{1}} /, / \overline{\mathrm{u}} /$ (open), and $/ \overline{\mathbf{a}} /$ (closed). Short vowels are: kasrah /i/, d' ammah /u/ (open) and fath 'ah /a/ (closed). Short vowels followed most of Arabic sounds, mutaharic sounds. The absence of the short vowel is called Sukūn $\left[{ }^{\circ}\right]$ and the sounds that are not followed by sukūn are called sakin sounds, for example, katab $^{\circ}$ (kataba) [16], [17]. In the current analysis, two common faithfulness constraints, MAX and IDEN, and nine markedness constraints that are suggested by this paper. These constraints are:

1. MAX-V: It prevents deletion of vowels.

2. IDEN-V: It prevents substituting vowels.

3. SAK: It prevents sequencing of two sakin sounds.

4. COMB: It prohibits combining short and long forms of the same vowel $\left({ }^{*} \mathrm{u}+\overline{\mathrm{u}}, *_{\mathrm{i}}+\overline{\mathrm{i}} \& *^{*} \mathrm{a}+\overline{\mathrm{a}}\right)$.

5. SEQU-(FAMILY): It is a family of constraints that prohibit sequencing of some vowels in some positions:

a. SEQU- $(\mathrm{a}+\overline{\mathrm{i}} / \overline{\mathrm{u}})$ : The short vowel $/ \mathrm{a} /$ must not be followed by $/ \overline{1} /$ or $/ \overline{\mathrm{u}} /$.

b. SEQU-( $\left.\mathrm{i}+\overline{\mathrm{u}}^{\circ}\right)$ : The sakin sound $/ \overline{\mathrm{u}} /$ must not be preceded by $/ \mathrm{i} /$.

c. SEQU-(Fi+̄): The long vowel $/ \overline{\mathrm{u}} /$ must not be preceded 
by /i/ at a final position.

d. SEQU-(iūāa): The long vowel / $\overline{\mathrm{u}} /$ must not be between $/ \mathrm{i} /$ and $/ \bar{a} /$.

e. SEQU-( $\left(\overline{\mathrm{l}}^{\circ} / \overline{\mathrm{u}}+\mathrm{i} / \mathrm{u}\right)$ : The sakin vowels, $\overline{\mathrm{l}}^{\circ}$ and $\overline{\mathrm{u}}^{\circ}$, must not be followed by $/ \mathrm{i} /$ or $/ \mathrm{u} /$.

f. SEQU-( $\left(\mathrm{u}+\overline{1}^{\circ}\right)$ : The sakin vowel $/ \overline{1}^{\circ} /$ must not be preceded by $/ \mathrm{u} /$.

j. SEQU $-(\mathrm{Fi} / \mathrm{u}+\overline{\mathrm{i}} / \overline{\mathrm{u}}+\mathrm{i} / \mathrm{u})$ : In the final position, the long vowels, $/ \overline{1} /$ or $/ \overline{\mathrm{u}} /$, must not be preceded and followed in the same time by the short vowels, $/ \mathrm{i} /$ or $/ \mathrm{u} /$.

\section{Data Analysis and Results}

These constraints are discussed in four cases of derivation as follows:

1. When two sakin sounds combine and the first one is a long vowel, $/ \overline{\mathrm{a}} /, / \overline{\mathrm{i}} /$, or $/ \overline{\mathrm{u}} /$, it will be deleted. Consider the following examples:

*naāom ${ }^{\circ}(\dot{\rho}) \rightarrow$ nam $^{\circ}($ نَ)

*quūं $\mathrm{m}^{\circ}$ (قُ)

*biīํำ
Table 1. The word nam ${ }^{\circ}(ن)$

\begin{tabular}{clll}
\hline$/ \mathbf{n a a}{ }^{\circ} \mathbf{m} /$ & SAK & MAX-V & COMB \\
\hline & $\begin{array}{l}\text { (a) } \text { naā }^{\circ} \mathrm{m}^{\circ} \\
\text { (b) } \text { nam }^{\circ}\end{array}$ & $* !$ & $*$ \\
\hline
\end{tabular}

In this table, two candidates compete to be selected through interaction of three constraints. The candidate (a) makes a fatal violation of SAK which is so fundamental in Arabic. In addition, the candidate also violates COMB by combining /a/ and $\bar{a}$. Therefore, it is excluded from the competition. The optimal candidate records a violation of the faithfulness constraint MAX-V. The markedness constraint SAK will continue to the next step although it has no role, but to show its importance and high rank. It is clear that SAK determines MAX-V and COMB. Ranking of the constraints for this input will be SAK $>>M A X-V>>C O M B$.

2. The two long mutaharic vowels, $/ \overline{\mathrm{u}} /$ and $/ \overline{\mathbf{1}} /$, will be replaced by the long vowel $/ \bar{a} /$ if they are preceded by the short vowel $/ \mathrm{a} /$, as in the following examples:

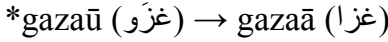

*baīaS (بَّ)

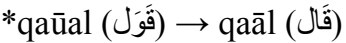

Table 2. The word gazaā (غزا)

\begin{tabular}{llllll}
\hline /gazaū/ & SAK & MAX-V & SEQU - a ā & IDEN-V & COMB \\
\hline (a) gazaū & & & $* !$ & $*$ & $*$ \\
(b) gazaā & & $* !$ & & \\
(c) gaza & $* !$ & $* !$ & & \\
(d) gazā & $* !$ & & & \\
\hline
\end{tabular}

The table contains four candidates and five constraints that are ranked to select the optimal candidate. The three candidates, (a), (c) and (d) are excluded by the fatal violations of SEQU-(aū) for (a), MAX-V for (c) and SAK and MAX-V for (d). The constraints IDEN-V and COMB are dominated by MAX-V and SEQU-(aū) which are dominated in turn by SAK, as follow: SAK >> MAX-V, SEQU-(aū)>>
IDEN-V and COMB.

3. The vowel $/ \overline{\mathbf{u}} /$ will be replaced by $/ \overline{\mathbf{i}} /$ if it is preceded by /i/ in four positions:

a. When / $\overline{\mathrm{u}} /$ is sakin and preceded by $/ \mathrm{i} /$, as in:

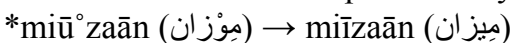

*miūo qaāt (موقات) $\rightarrow$ miīqāat (ميقات)

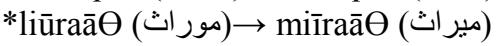

Table 3. The word miżzaān (ميزان)

\begin{tabular}{|c|c|c|c|c|c|}
\hline$/ \mathbf{m i u ̄}^{\circ} \mathbf{z a a ̄ n}$ / & SAK & MAX-V & $\operatorname{SEQU}\left(\mathbf{i}+\overline{\mathbf{u}}^{\circ}\right)$ & IDEN-V & СОМВ \\
\hline (a) miū zaān & & & $* !$ & & $*$ \\
\hline (b) $\operatorname{miū}^{\circ} \mathrm{zan}$ & & & $* !$ & $*$ & \\
\hline (c) miī zaān & & & & * & $* *$ \\
\hline (d) mizaān & & $* !$ & & & * \\
\hline (e) $\min ^{\circ} \mathrm{zan}$ & & $* !$ & & & \\
\hline (f) mizan & & $* * !$ & & & \\
\hline
\end{tabular}

The current table includes five constraints that interact to select the optimal candidate among the six competitors. As it is shown, the fata violation of the MAX-V by (d), (e) and (f) puts them out of the competition. In the same context, SEQU $\left(\mathrm{i}+\overline{\mathrm{u}}^{\circ}\right)$ excludes (a) and (b). The winner is (c) because it is not fatally violated. The constraints are ranked as follows:
SAK $>>$ MAX-V, SEQU $\left(i+\overline{\mathrm{u}}^{\circ}\right)>>$ IDEN-V $>>$ COMB

b. When $/ \overline{\mathrm{u}} /$ is at the end and preceded by $/ \mathrm{i} /$, as in:

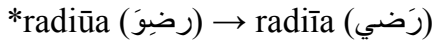

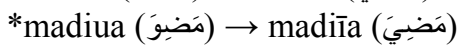

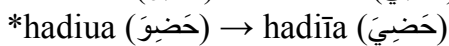


Table 4. The word radiīa (رضى )

\begin{tabular}{|c|c|c|c|c|c|}
\hline /radiūa/ & SAK & MAX-V & SEQU $(\mathbf{F i}+\overline{\mathbf{u}})$ & IDEN-V & $\mathrm{COMB}$ \\
\hline $\begin{array}{ll}\text { (a) radiūa } \\
\text { (b) radiīa } \\
\text { (c) radia }\end{array}$ & & $* !$ & $* !$ & * & $\begin{array}{l}* \\
*\end{array}$ \\
\hline
\end{tabular}

This table consists of five constraints, two faithfulness (IDEN-V) and markedness constraints (SAK, COMB, and SEQU $(F i+\bar{u}))$. MAX-V puts the candidate (a) out of the competition and SEQU $(\mathrm{Fi}+\overline{\mathrm{u}})$ does so with (c). The winner is (b) which violates IDEN-V and COMB. The constraints are ranked as follows: SAK $>>$ MAX-V, SEQU $(\mathrm{Fi}+\overline{\mathrm{u}})>>$
IDEN-V $>>$ COM B

c. When $/ \overline{\mathrm{u}} /$ is placed between $/ \mathrm{i} /$ and $/ \overline{\mathrm{a}} /$, it will be substituted by $/ \overline{1} /$, as in:

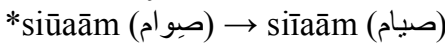

*siūaāq (سبواق) $\rightarrow$ siīaāq (سِياق)

*āinqiūaād (إنقِق ادِ (إِقِياد)

Table 5. The word sīaām (صيام)

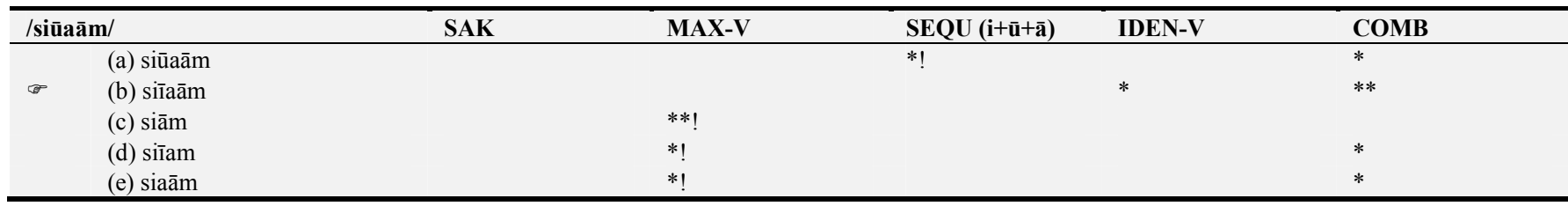

The table involves five competitors that are constrained by two faithfulness constraints (MAX-V and IDEN-V) and three markedness ones (SAK, COMB and SEQU $(i+\bar{u}+\bar{a}))$. MAX$\mathrm{V}$ leads three candidates (c, d, e) out of the competition because its violation was fatal. The candidate (a) is excluded by a fatal violation of SEQU $(i+\overline{\mathrm{u}}+\overline{\mathrm{a}})$ in addition to violating COMB. The winner is (b) which violates IDEN-V for one time and COMB twice. The constraints are ranked as follows: SAK $>>$ MAX-V, SEQU $(i+\overline{\mathrm{u}}+\overline{\mathrm{a}})>>$ IDEN-V $>>$ COMB.

d. When $/ \overline{1} /$ and $/ \overline{\mathrm{u}} /$ come together and the first is sakin, $/ \overline{\mathbf{1}} /$ or $/ \overline{\mathrm{u}} /, \overline{\mathrm{u}}$ will be converted to $/ \overline{\mathbf{1}} /$, as in:

*mar maūīun (مَرْمَويّ)

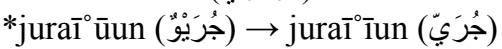

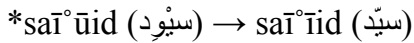

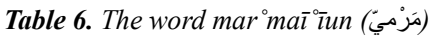

\begin{tabular}{|c|c|c|c|c|c|}
\hline$/$ mar $^{\circ} \mathbf{m a u ̄}{ }^{\circ} \overline{\mathbf{i} u n} /$ & SAK & MAX-V & SEQU $(a+\overline{1})$ & $\operatorname{SEQU}\left(\left(^{\circ} / \overline{\mathbf{u}}^{\circ}+\overline{\mathbf{u}} / \overline{\mathbf{I}}\right)\right.$ & IDEN-V \\
\hline $\begin{array}{l}\text { (a) } \operatorname{mar}^{\circ} \operatorname{maū}^{\circ} \bar{i} u \\
\text { (b) mar maīi } \\
\text { (c) mar }{ }^{\circ} \text { maīun }\end{array}$ & & $* !$ & $* !$ & $* !$ & * \\
\hline
\end{tabular}

In this table, there are three candidates and five constraints. The competitors (a) and (b) are losers because of their fatal violations of SEQU $\left(\overline{1}^{\circ} / \overline{\mathrm{u}}^{\circ}+\overline{\mathrm{u}} / \overline{\mathbf{1}}\right)$ for (a) and MAX-V and SEQU $(a+\overline{1})$ for $(c)$. The optimal choice is (b) which violates only IDEN-V. The ranking of the constraints will be as follows: SAK $>$ MAX-V, SEQU $(a+\overline{1})$, SEQU $\left(\overline{1}^{\circ} / \overline{\mathrm{u}}^{\circ}+\overline{\mathrm{u}} / \overline{\mathrm{i}}\right)>>$ IDEN-V.

4. The sound $/ \overline{\mathbf{1}} /$ will be replaced by $/ \overline{\mathrm{u}} /$ if it is sakin and preceded by the short vowel /u/, as in:

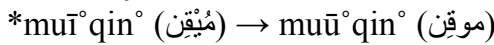

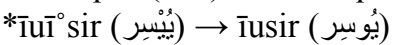

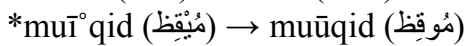

Table 7. The word muй ${ }^{\circ}$ in ${ }^{\circ}$ (موقن)

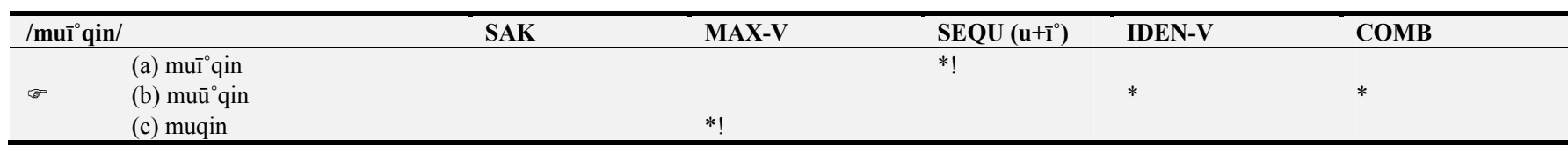

The interaction in this table is among five constraints to select the optimal one among the three candidates. The winner in this competition is (b) which violates IDEN-V and COMB. The losers are (a) because of its fatal violation of SEQU $\left(u+i^{\circ}\right)$ and (c) which does so with MAX-V. The ranking will be as follows: $\operatorname{SAK}>>\operatorname{MAX}-\mathrm{V}, \operatorname{SEQU}\left(\mathrm{u}+\overline{1}^{\circ}\right)>>$
IDEN-V, COMB.

5. Mutaharic vowels, $\overline{1}$ or $\overline{\mathrm{u}}$, will be sakin when they are located at the end and preceded by a short vowel, $\mathrm{i}$ or $\mathrm{u}$, as in:

*jānin̄i (جاني) jāniīo (جانِي)

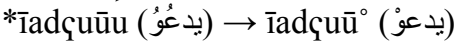

*qaādī̄u (قاضِيُ) q qaādī̄o (قاضِيْ)

Table 8. The word jāniī (جاني)

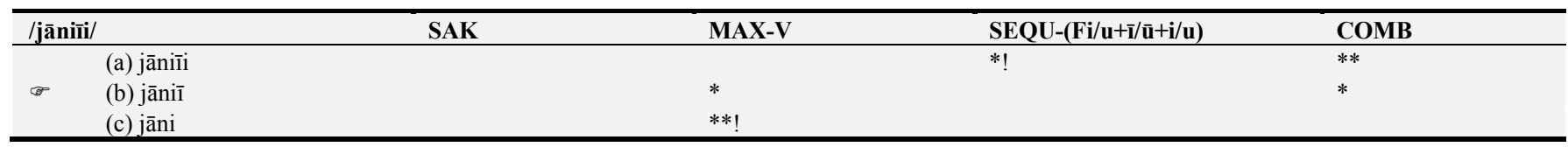


The table above contains three candidates and four constraints. The competitors (a) and (c) are the losers. The candidate (a) is led out of the conflict by the fatal violation of the markedness constraint, SEQU-(Fi/ $/ \mathrm{u}+\overline{\mathbf{i}} / \overline{\mathrm{u}}+\mathrm{i} / \mathrm{u})$, in addition to recording two violations of COMB. The second loser (c) is excluded as a result to its violation of MAX-V twice. The winner, (b), violates the faithfulness constraint MAX-V and the markedness constraint COMB. The constraints ranking will be: $\mathrm{SAK} \gg>\mathrm{MAX}-\mathrm{V}, \mathrm{SEQU}-(\mathrm{Fi} / \mathrm{u}+\overline{\mathrm{i}} / \overline{\mathrm{u}}+\mathrm{i} / \mathrm{u})>>\mathrm{COMB}$.

\section{The General Ranking}

The previous section shows how the constraints are ranked in the different cases of derivation regarding vowels. This section represents the constraints as a whole in one package. It is clear that the suggested markedness constraint SAK is the most dominant, therefore it will be on the top of the hierarchy. At a lower level, two constraints come together, the faithfulness constraint MAX-V and the markedness family of constraints SEQU-(FAMILY). These constraints dominate the faithfulness constraint IDEN-V which in turn dominates the markedness constraint COMB. The final ranking of the whole constraints will be as follows: $\mathrm{SAK}>>$ MAX-V, SEQU-(FAMILY) $>>$ IDEN-V $>>$ COMB.

\section{Conclusions}

In light of what has been investigated above, the paper arrives at the following conclusions:

1. Vowels in Arabic derivation are subjected to a complex system of conflicted (two) faithfulness constraints and (nine) markedness constraints that have a peculiar ranking.

2. This system of ranked constraints $(\mathrm{SAK}>>\mathrm{MAX}-\mathrm{V}$, SEQU-(FAMILY) $>>$ IDEN-V $>>$ COMB) is part of the general ranking of speech production of Arabic. This ranking prevents deriving or forming words that violate sounds combination patterns of Arabic.

3. SAK, SEQU-(FAMILY) and COMB are markedness constraints that can be added to the storage of the discovered universal constraints.

4. Some markedness constraints, like SAK, occupy a higher position and play a greater role in producing words. Ranking such constraints a decisive position gives a kind of peculiarity to Arabic.

\section{References}

[1] Bradley, T. (2014). Optimality Theory and Spanish Phonology. Language and Linguistics Compass, 8, 65-88.
[2] Haro, A. H. (2020). The vowel /u/ before deleted word-final $/ \mathrm{s} /, / \mathrm{r} /$, and $/ \theta /$ in Eastern Andalusian Spanish.

[3] Prince, A. \& Smolensky, P. (1993, 2004). Optimality Theory: Constraint Interaction in Generative Grammar. Oxford: Blackwell.

[4] Archangeli, D. (1997). Optimality theory: an introduction to linguistics in the 1990s. In Diana Archangeli and Terence Langendoen (eds.). Optimality Theory: An Overview. Cambridge: Blackwell.

[5] Chomsky, N. and Halle, M. (1968). The Sound pattern of English. New York: Harper and Row.

[6] Boersma, P., Dekkers, J. \& Weijer, J. (eds.). (2000). Optimality Theory: Phonology, Syntax, and Acquisition. Oxford: Oxford University Press.

[7] Kager, R. (2004). Optimality Theory. Cambridge: Cambridge University Press.

[8] Baković, E. (2013). Blocking and Complementarity in Phonological Theory. United Kingdom: Equinox eBooks Publishing.

[9] Barke, S., Kunkel, R., Polikarpova, N., Meinhardt, E., Bakovic, E., \& Bergen, L. (2019). "Constraint-based Learning of Phonological Processes." Proceedings of the 2019 Conference on Empirical Methods in Natural Language Processing and 9th International Joint Conference on Natural Language Processing (EMNLP-IJCNLP 2019).

[10] Lacy, P. (2007). Themes in phonology. In Paul de Lacy (ed.), The Cambridge Handbook of Phonology. Cambridge: Cambridge University Press.

[11] Hale, M. and Ress, C. (2008). The Phonological Enterprise. Oxford: Oxford University Press.

[12] McCarthy, J. (2002). A Thematic Guide to Optimality Theory. Cambridge: Cambridge University Press.

[13] Chomsky, N. (1973). Conditions on transformations. In Stephen Anderson and Paul Kiparsky (ed.). A Festschrift for Morris Halle. New York: Holt, Rinehart and Winston.

[14] McCarthy, J. (ed.). (2004). Optimality Theory in Phonology: A Reader. Malden, MA: Blackwell publishing.

[15] McCarthy, J. \& Prince, A. (1995). Faithfulness and reduplicative identity. In Jill Beckman, Laura Walsh-Dickey \& Suzanne Urbanczyk (eds.), University of Massachusetts occasional papers in linguistics Vol. 18. Amherst: GLSA Publications.

[16] Abu-Chacra, F. (2007). Arabic: An Essential Grammar. London: Routledge.

[17] Watson, J. (2002). The Phonology and Morphology of Arabic. Oxford: Oxford University Press. 